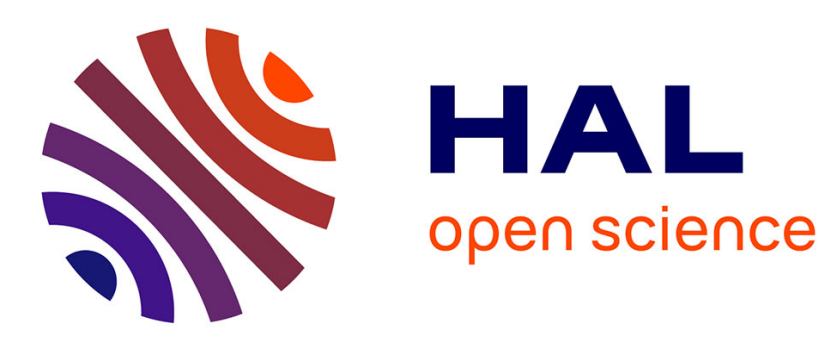

\title{
Erosion wear behaviour and model of abradable seal coating
}

\author{
Yi Maozhong, Huang Baiyun, He Jiawen
}

\section{To cite this version:}

Yi Maozhong, Huang Baiyun, He Jiawen. Erosion wear behaviour and model of abradable seal coating. Wear, 2002, 252 (1-2), pp.9-15. 10.1016/S0043-1648(01)00681-0 . hal-01555293

\section{HAL Id: hal-01555293 \\ https://hal.science/hal-01555293}

Submitted on 6 Jul 2017

HAL is a multi-disciplinary open access archive for the deposit and dissemination of scientific research documents, whether they are published or not. The documents may come from teaching and research institutions in France or abroad, or from public or private research centers.
L'archive ouverte pluridisciplinaire HAL, est destinée au dépôt et à la diffusion de documents scientifiques de niveau recherche, publiés ou non, émanant des établissements d'enseignement et de recherche français ou étrangers, des laboratoires publics ou privés. 


\title{
Erosion wear behaviour and model of abradable seal coating
}

\author{
Yi Maozhong ${ }^{\mathrm{a}}$, Huang Baiyun ${ }^{\mathrm{a}}$, He Jiawen ${ }^{\mathrm{b}}$ \\ a State Key Laboratory for Powder Metallurgy, Central South University of Technology, Changsha 410083, PR China \\ b State Key Laboratory for Mechanical behaviour of Metallic Material, Xi'an Jiaotong University, Xi'an 710049, PR China
}

\begin{abstract}
The abradable seal coating for an aircraft turbine engine is mostly composed of metal phase, self-lubricating non-metal phase and many pores. The erosion wear resistance is one of the most important properties of the coating. The erosion wear behaviour and mechanism of several kinds of middle temperature seal coatings were investigated by a CMS-100 self-made vacuum sand erosion machine. The results show that the relationship between the erosion mass loss and the erosion time is linear, the coatings hold a maximum erosion rate at $60^{\circ}$ impact angle, and the relation between the erosion rate and the impact speed is an exponential function. The speed exponent increases with the increase of the impact angle. At $90^{\circ}$ impact, the abrasive particles impinging on the coating surface produce indentations and extruded lips, and then the lips are work-hardened and fall off; and flattened metal phase grains are impacted repeatedly, loosed and debonded. At $30^{\circ}$ impact, the micro-cutting, plowing and tunneling via pores and non-metal phase are involved. The model of the erosion mechanism is advanced on the basis of the above-mentioned erosion wear behaviour.
\end{abstract}

Keywords: Abradable seal coating; Erosion wear; Mechanism; Model

\section{Introduction}

The clearance between the rotating blades and the casing should be as small as possible in order to increase the efficiency and reduce the fuel consumption of an aircraft turbine engine [1]. The gas path sealing has become an important method for this purpose [2]. The thermal sprayed abradable seal coating has been used because of its simple manufacturing processes, easy repair of the components, easy adjustment of its properties and good sealing effectiveness [2]. Also, it can provide thermal barrier for the casing, and reduce the influence of the high temperature fuel gas on the casing [2,3]. The coating is one kind of composite material composed of metal phase, self-lubricating non-metal phase and many pores [4]. In application, it is required that the rotor blades scrape the coating to form a minimum clearance. So the coating should be not only soft enough to be easily scraped without damaging the blades-good abradability, but also hard enough to resist against the erosion by the high speed gas flow and the solid particles in the gas-good erosion resistance [3-6]. The abradability and erosion resistance are the most important properties of the coating. But they are contradictory $[5,6]$, and the coating should provide a good balance between the abradability and the erosion resistance.

The researchers and users have paid attention to the study [5-9] of the powders, spray processes, properties of the coating and the relationship among them. But, the basic researches about the abradability and the erosion resistance have not been well-made [4,10,11]. Especially, the research about the erosion wear behaviour of the coatings has not been much reported. Because of high porosity and much non-metal phase in the coating, its erosion wear rule and behaviour can be different from those of bulk material and some coatings. So it is imperative to study its rule and behaviour. In this paper the erosion wear rule and mechanism of several kinds of middle temperature abradable seal coatings were investigated, and the model of the erosion wear was advanced.

\section{Experimental method}

The sprayed powders were METCO $307(75 \% \mathrm{Ni}+25 \%$ graphite G), METCO $310(57 \% \mathrm{Al}+8 \% \mathrm{Si}+35 \% \mathrm{G})$, METCO $313(40 \% \mathrm{Al}+5.5 \% \mathrm{Si}+45.5 \% \mathrm{G}+9 \%$ organic binder) and METCO $601(40 \%$ polyester $+60 \% \mathrm{Al}-\mathrm{Si}$ alloy), which were made by METCO, USA. The sprayed coating specimens were called M307, M310, M313 and 
Table 1

Microstructure and hardness of coating specimens

\begin{tabular}{llllr}
\hline Specimen & $\begin{array}{l}\text { Metal } \\
\text { phase }(\%)\end{array}$ & $\begin{array}{l}\text { Non-metal } \\
\text { phase }(\%)\end{array}$ & $\begin{array}{l}\text { Porosity } \\
(\%)\end{array}$ & HR15y \\
\hline M307-1 & 43.7 & 25.9 & 30.4 & 18 \\
M307-2 & 46.8 & 26.0 & 27.2 & 20 \\
M307-3 & 53.6 & 27.3 & 19.1 & 60 \\
F307-1 & 35.3 & 31.6 & 33.1 & -52 \\
F307-2 & 39.1 & 28.3 & 32.6 & -34 \\
F307-3 & 46.6 & 26.1 & 27.3 & -20 \\
M301-1 & 43.9 & 20.4 & 35.7 & -12 \\
M301-2 & 62.9 & 14.5 & 7.6 & 28 \\
F301-1 & 82.5 & 13.0 & 4.5 & 73 \\
F310-2 & 78.8 & 16.5 & 4.7 & 57 \\
M313-1 & 74.0 & 18.3 & 7.7 & 74 \\
M313-2 & 70.1 & 21.8 & 8.1 & 70 \\
M313-3 & 74.9 & 17.9 & 7.2 & 77 \\
F313 & 62.7 & 26 & 11.3 & 57 \\
M601-1 & 29.4 & 69.3 & 1.3 & 51 \\
M601-2 & 34.1 & 65.2 & 1.7 & 53 \\
F601 & 53.9 & 44.6 & 1.5 & 65 \\
\hline
\end{tabular}

M601, respectively. Four kinds of powders made in China, which were slightly different from the corresponding METCO powders in composition, were also used. The coating specimens prepared by the powders made in China were called F307, F310, F313 and F601, respectively. M307 and F307 were called 307 type of coating. The others are similar. M307, F307, M310 and F310 coatings were sprayed on the blasted surface of the low carbon steel plate by a METCO-6P flame spray system. M313, F313, M601 and F601 coatings were sprayed by a METCO-7MB plasma spray system. Specimens with different microstructure and hardness were prepared for each kind of powder by changing spray parameters. The microstructure and hardness of the coating specimens are listed in Table 1. Fig. 1 shows the microstructure in cross section of M310-2 coating, where the white matrix is AlSi alloy, the grey phase is graphite, the black phase is pore.

Erosion wear test was made on a CMS-100 self-made erosion machine. Fig. 2 shows the schematic diagram of the

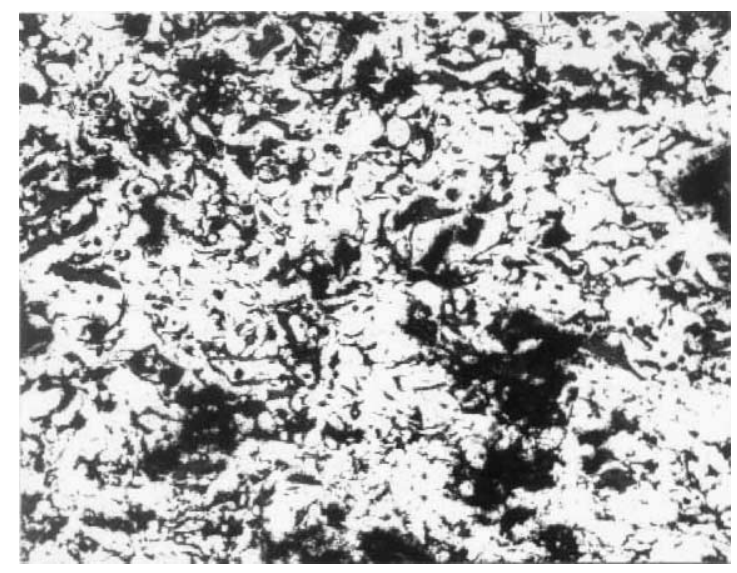

Fig. 1. Microstructure in cross section of M310-2 coating.

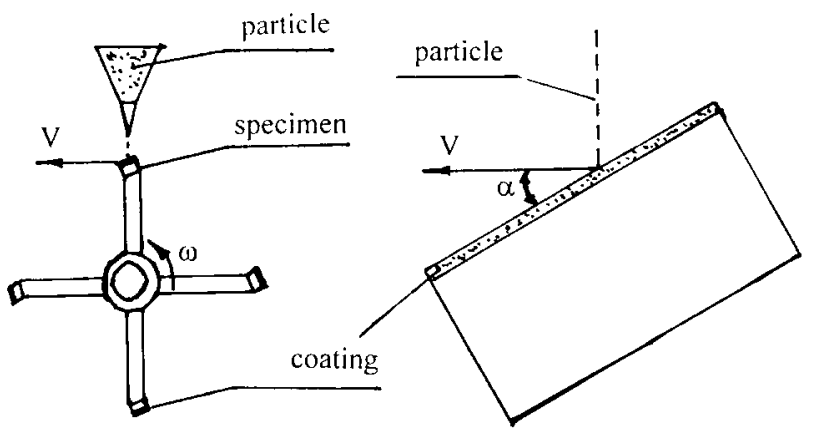

Fig. 2. Schematic diagram of erosion tester.

machine. The specimen to be tested and abrasive particle are in a $1.3-6.5 \mathrm{~Pa}$ vacuum chamber. The abrasive particle was 100 mesh corundum whose feeding rate was $16 \mathrm{~g} / \mathrm{min}$. The impact angles were $30^{\circ}, 60^{\circ}$ and $90^{\circ}$. Because the mean velocity of $0.15-0.30 \mathrm{~mm}$ diameter solid particles in the gas flow with $150 \mathrm{~m} / \mathrm{s}$ velocity is $30-70 \mathrm{~m} / \mathrm{s}$ [12], the impact test speeds were $20-80 \mathrm{~m} / \mathrm{s}$, The impact speed is the linear velocity of rotaive specimen. Erosion time is $1 \mathrm{~h}$, but the time and impact speed were changed for some specimens. The ratio of the mass loss of the specimen to the mass of the grit is called erosion rate, $E$ in $\mathrm{mg} / \mathrm{g}$.

\section{Experimental results and discussion}

\subsection{Rule of erosion wear}

\subsubsection{Effect of erosion time}

The relationship between the mass loss and the erosion time at given impact angles is linear, as shown in Fig. 3. This indicates that the erosion rate of the coatings is not related to the erosion time under the same erosion condition, such

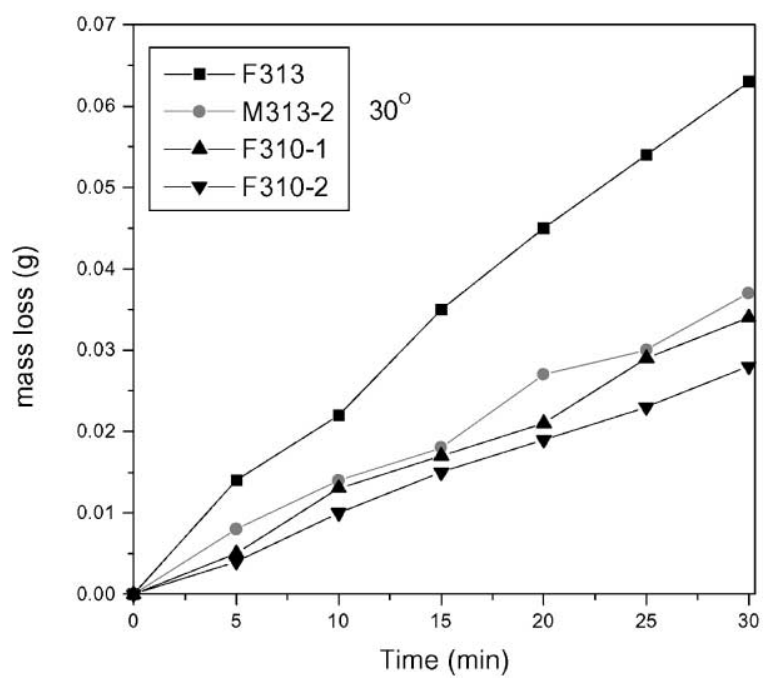

Fig. 3. Mass loss versus impact time. 
as impact angle, erosion speed, the kind and size of abrasive particles. Meanwhile, the relationship indicates that the erosion rate is related to the characteristics of the coatings, such as their kind, microstructure and hardness, but it is not related to the thickness of the coatings. Therefore, the erosion rate can act as a basis of the design of coating lifetime under the given systematic parameters.

Bulk materials and some coatings have an erosion inoculation period, that is, the mass loss does not occur immediately at the initial impact $[13,14]$. Only if the strain caused by impinging particles accumulates to a critical value, can the metal grains on the impacted surface of the materials fall off and the mass loss appear, and then the erosion rate transits gradually to a stable state. But, the rate at the initial stage of the erosion for the abradable seal coating becomes the stable state, which is related to high porosity, a large volume fraction of non-metal phase and weak adhesion between metal grains in the coating. This is the peculiar erosion behaviour of the abradable seal coating.

\subsubsection{Effect of impact angle}

Fig. 4 shows the erosion rate versus impact angle, and the rate of all tested specimens is largest at $60^{\circ}$.

According to the common rule of the erosion rate with the change of impact angle $\alpha$, the erosion wear can be divided into plastic material wear and brittle material wear. The relationship [13] between erosion rate and impact angle is

$E=A \cos ^{2} \alpha \sin (m \alpha)+B \sin ^{2} \alpha$

where $m, A$ and $B$ are constants. For typical brittle material, $A$ is equal to zero and the erosion rate is largest at $90^{\circ}$ impact angle. For typical plastic material, $B$ is equal to zero and the erosion rate is largest at $20-30^{\circ}$ impact angle. Therefore, the erosion behaviour of the abradable seal coating is between the behaviour of the plastic material and that of the brittle material.

Because hardness of the seal coating, in which the metal phase resisting erosion wear is typical plastic material, is

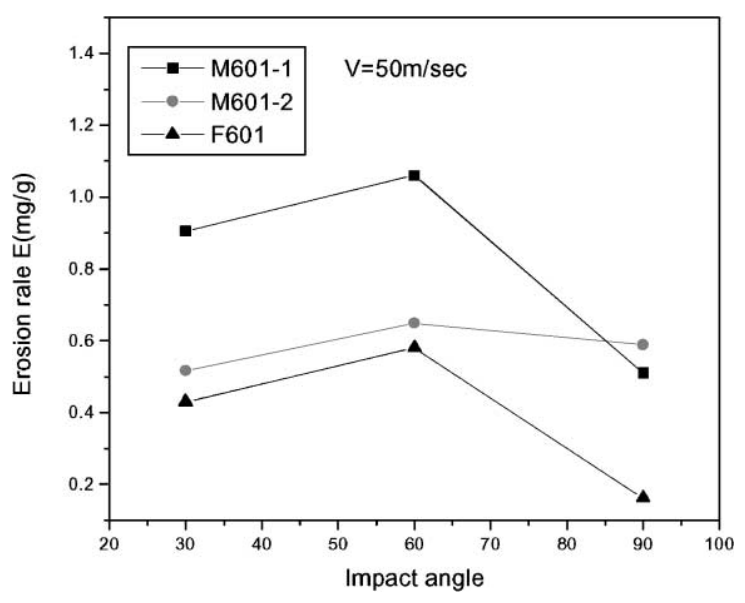

Fig. 4. Effect of impact angle on erosion rate.

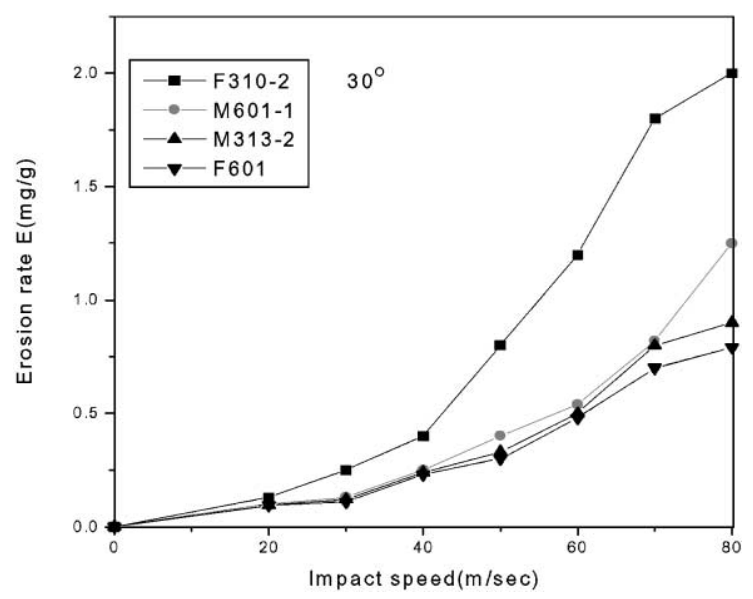

Fig. 5. Effect of impact speed on erosion rate.

very low, the erosion wear is mainly micro-cutting and plowing at low impact angle. On the other hand, because the normal impact on the surface of the coating increases with the increase of impact angle, and because the coating holds high porosity, weak adhesion between metal phase grains and a large amount of non-metal phase, which are like cracks, the erosion wear behaviour of the coating is similar to that of the brittle material. Therefore, the erosion rate of the coating is largest at $60^{\circ}$ impact angle.

\subsubsection{Effect of impact speed}

Fig. 5 shows the relationship between erosion rate $E$ and impact speed $V$ at $30^{\circ}$ impact angle. The regression analysis shows

$E=C V^{n}$

where $C$ is constant, $n$ is speed exponent. Table 2 lists $C$ and $n$ values at different impact angles. Table 2 indicates that the speed exponent depends on the impact angle. The different exponents result from different mechanisms of the erosion wear at different impact angles. The value of $n$ increases with the increase of impact angle. This shows that the increase of impact speed results in the remarkable increase of the erosion rate, the maximum mass loss moves to a higher angle with the increase of impact speed. Therefore, the coating basically displays its erosion behaviour as a brittle material. At low impact angle, the speed exponent of the coating is close to that of plastic material. However, at 60 and $90^{\circ}$, the exponent $n$ is larger than that of brittle material [13].

\subsection{Erosion wear mechanism and model}

Fig. 6(a) and (b) show respectively the surface morphology of F601, M313-2 coatings impacted at $90^{\circ}, 50 \mathrm{~m} / \mathrm{s}$. The indentations and extruded lips on the surface of the metal phase in the coating are clearly seen in the figures. The adhesion between some lips and the metal phase matrix is weak, and the lips easily fall off by repeated impact. Therefore, 
Table 2

Result of regression analysis of relationship between erosion rate and impact speed

\begin{tabular}{|c|c|c|c|c|c|c|}
\hline \multirow[t]{2}{*}{ Specimen } & \multicolumn{2}{|l|}{$30^{\circ}$} & \multicolumn{2}{|l|}{$60^{\circ}$} & \multicolumn{2}{|l|}{$90^{\circ}$} \\
\hline & $C$ & $n$ & $C$ & $n$ & $C$ & $n$ \\
\hline F310-2 & $1.7 \times 10^{-4}$ & 2.01 & $7.88 \times 10^{-6}$ & 2.81 & $3.41 \times 10^{-6}$ & 3.01 \\
\hline M313-2 & $1.34 \times 10^{-4}$ & 2.04 & $9.59 \times 10^{-6}$ & 2.86 & $3.84 \times 10^{-6}$ & 3.02 \\
\hline M601-1 & $2.98 \times 10^{-4}$ & 2.02 & $6.69 \times 10^{-6}$ & 3.00 & $2.25 \times 10^{-6}$ & 3.22 \\
\hline F601 & $1.63 \times 10^{-4}$ & 1.96 & $6.35 \times 10^{-6}$ & 2.83 & $4.03 \times 10^{-6}$ & 2.96 \\
\hline
\end{tabular}

it is thought that at $90^{\circ}$ impact angle, the abrasive particles impact on the surface of the metal phase in the coating and produce indentations and extruded lips, and then the lips impacted repeatedly by abrasive particles become work-hardened and eventually fall off.

Otherwise, because of many pores and a large volume fraction of non-metal phase, which are like pre-cracks, the metal grains in the coating are separated by the pores and non-metal phase and become a non-continuous body, and the adhesion between the metal grains is weak. During normal impacting of the abrasive particles, the surface of the coating endures Hertz force, partial plastic deformation appears, and cracks initiate. The cracks propagate through the grain boundaries, and then the flattened metal grains on the coating surface loose and eventually fall off by repeated impact, as shown in Fig. 7.

Fig. 6(c) shows the surface morphology of M307-3 coating impacted at $90^{\circ}$ impact angle. It is clearly seen that the indentation effect for 307 coating is not so remarkable as that for 310,313 and 601 coatings at $90^{\circ}$. The reason is that the hardness of the metal phase in 307 coating is higher than that in 310, 313 and 601 coatings. In addition, the more important reason is that the flattened metal grains easily fall off by a few impacts because of higher porosity, a larger volume fraction of non-metal phase and weaker adhesion between metal grains in the 307 coatings. Therefore, the feature of

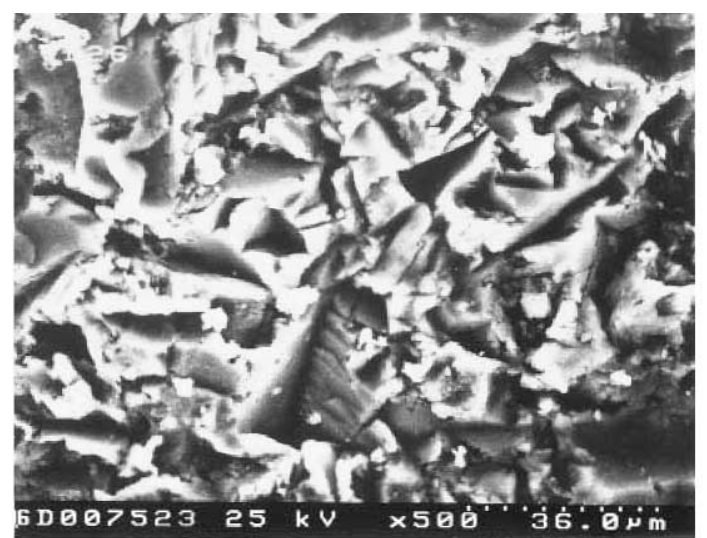

(a)

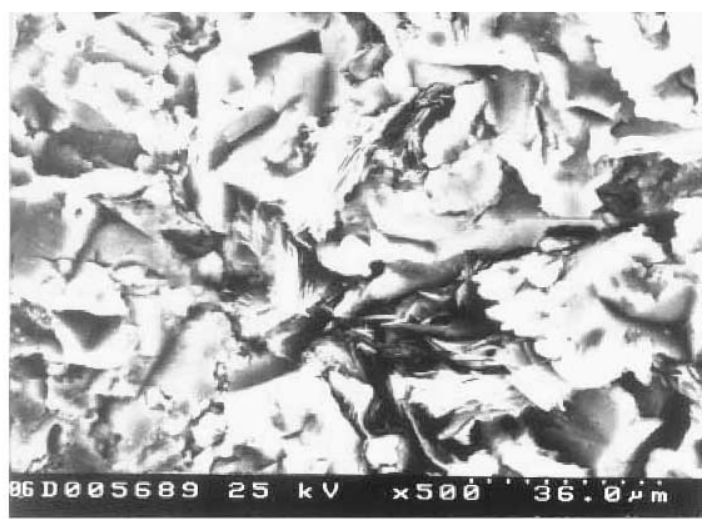

(b)

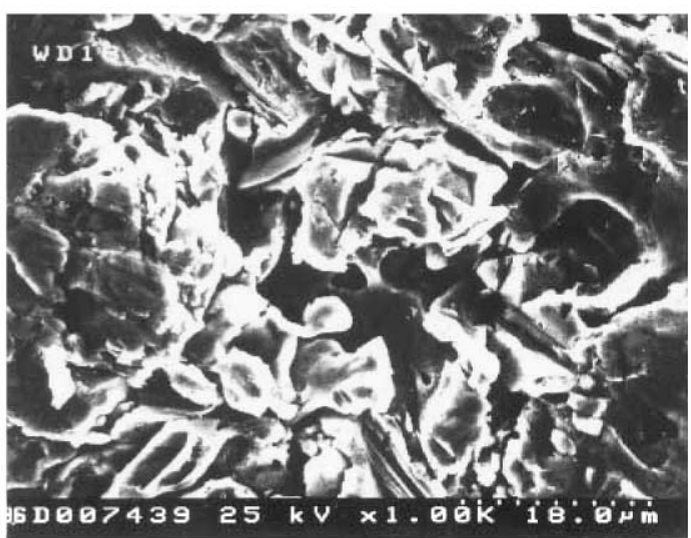

(c)

Fig. 6. Surface morphology of (a) F601; (b) M313-2; (c) M307-3 coating impacted at $90^{\circ}, 50 \mathrm{~m} / \mathrm{s}$. 


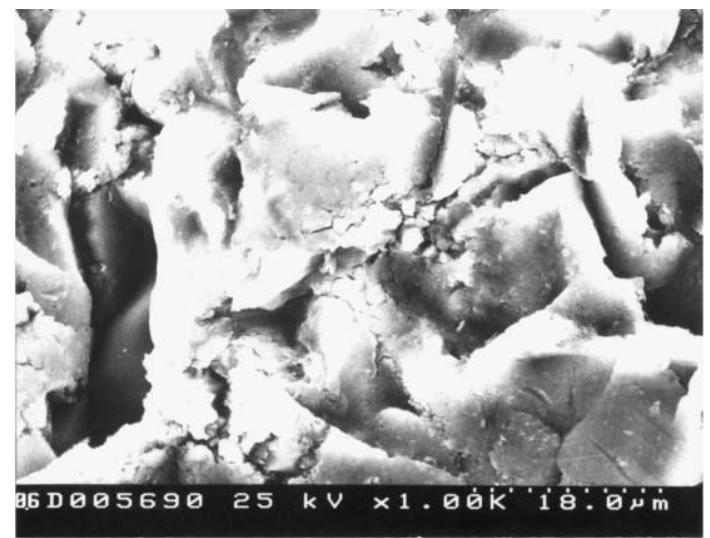

(a)

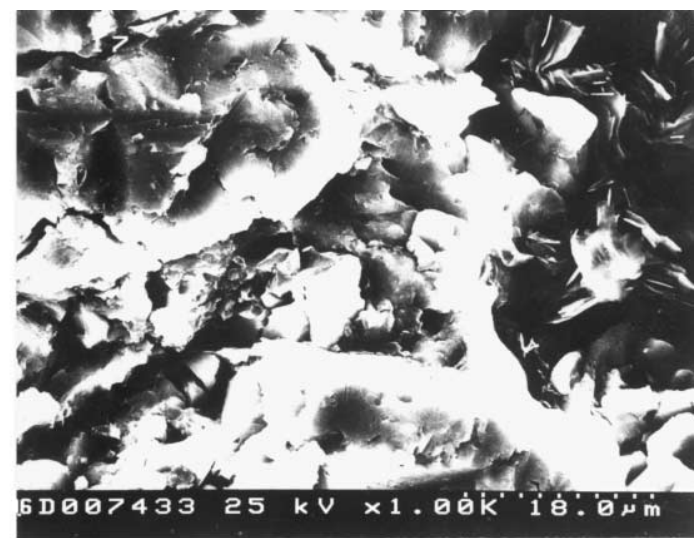

(b)

Fig. 7. (a) Crack on surface of F313 coating, (b) loosed metal phase grain of M313-2 coating impacted at $90^{\circ}, 50 \mathrm{~m} / \mathrm{s}$.

extruded lip on the surface of 307 coating is not remarkable, and the debond of the flattened metal grain occurs prior to the extruded lips produced by impact indentation effect.

Fig. 8(a) and (b) show the surface morphology of erosion worn M313, M601 coating at $90^{\circ}, 50 \mathrm{~m} / \mathrm{s}$ respectively. The pictures indicate that the graphite in coatings is impacted, fall off prior to metal phase, and leaves caves; but the polyester in 601 coating stays longer than the graphite in the other coatings because it can endure high elastic strain and absorb impact energy of abrasive particles. Because of the fall of the graphite in worn 307 coating and many pores, the surface morphology of the metal phase becomes loose, porous and honeycomb-like. This indicates that the erosion resistance of the graphite in the coatings is extremely low, and the polyester in 601 coating holds good erosion resistance.

The erosion wear mechanism of the abradable seal coating at $90^{\circ}$ impact is that (1) the abrasive particles impact and extrude the surface of the coating, and produce indentations and extruded lips, and then the lips eventually fall off; (2) the flattened metal phase grains in surface layer of the coating loosen and debond by repeated impact. The former effect is more remarkable in 310,313 and 601 coatings, and the latter effect is more remarkable in 307 coating. To sum up, the model of indentation and delamination of grains for the abradable seal coating at $90^{\circ}$ impact angle is put forward and shown in Fig. 9(a).

Fig. 10 $(\mathrm{a}-\mathrm{c})$ show respectively the surface morphology of erosion worn F313, M601-1 and M307-3 coatings at 30 , $50 \mathrm{~m} / \mathrm{s}$. Micro-cutting and plowing traces, and curled parts produced by cutting and plowing are observed in the figures. Cracks occur between the curled parts and the metal phase matrix. The curled parts are repeatedly impacted by impinging particles and easily fall off. This indicates that at lower impact angle, the micro-cutting and plowing caused by shear component of abrasive particles play a principal role. Fig. 10(b) shows also that the micro-cutting and plowing traces on the surface of erosion worn 601 coating are short, shallow and flat, because the polyester in the coating absorbs the partial energy of impinging particle. Compared with 310 , 313 and 601 coatings, the micro-cutting and plowing traces

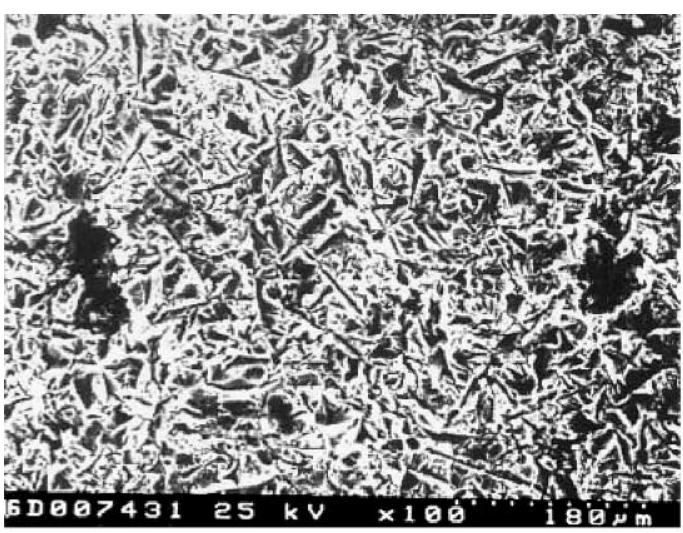

(a)

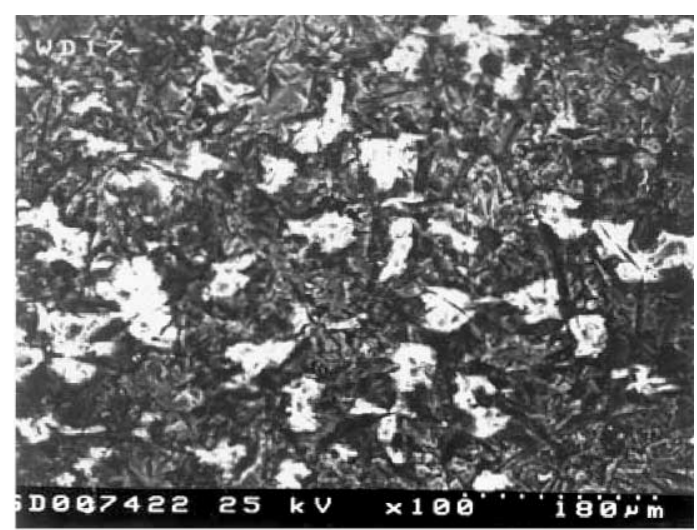

(b)

Fig. 8. Surface morphology of (a) M313; (b) M601 coating impacted at $90^{\circ}, 50 \mathrm{~m} / \mathrm{s}$. 


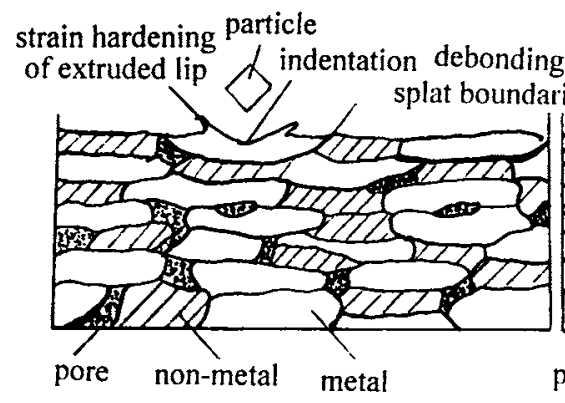

(a)

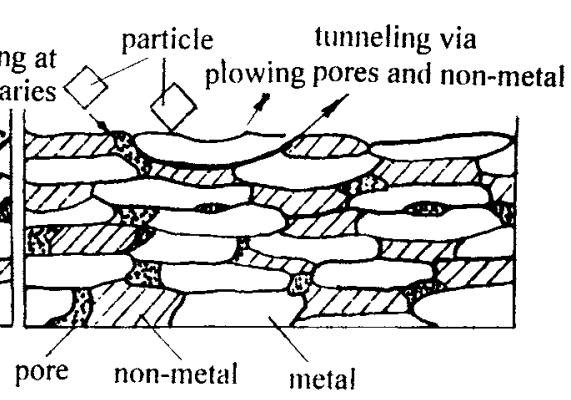

(b)

Fig. 9. Model of erosion wear (a) at $90^{\circ}$; (b) at $30^{\circ}$.

in 307 coating are shorter, more shallow and flatter, and the amount of curled parts is less in Fig. 10(c). The reason is higher hardness of metal phase $\mathrm{Ni}$, higher porosity and more non-metal phase in 307 coating. In addition, because of high porosity and a large volume fraction of non-metal phase, impinging particles produce tunneling via pores and non-metal phase during micro-cutting and plowing. This process accelerates the mass loss of the coating. The tunneling is more remarkable in 307 coating. Therefore, the mechanism of the erosion wear of the abradable seal coating at $30^{\circ}$ impact angle is micro-cutting, plowing and tunneling via pores and non-metal phase, and the model is shown in Fig. 9(b).

Fig. 11 shows the morphology of erosion worn F313-1 coating at $60^{\circ}, 50 \mathrm{~m} / \mathrm{s}$. It is clearly seen that the traces of micro-cutting and plowing are not so shallow and flat as those at $30^{\circ}$, and the indentation and extruded lips are not so remarkable as those at $90^{\circ}$. So, erosion at $60^{\circ}$ is somewhere in between that at $30^{\circ}$ and that at $90^{\circ}$.

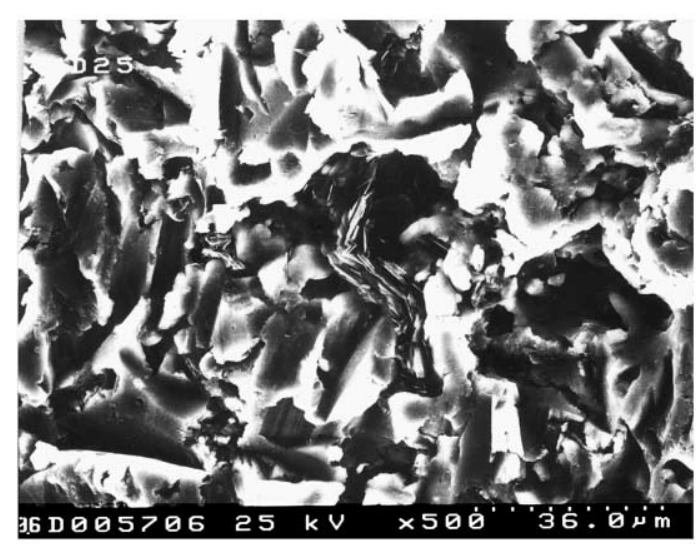

(a)

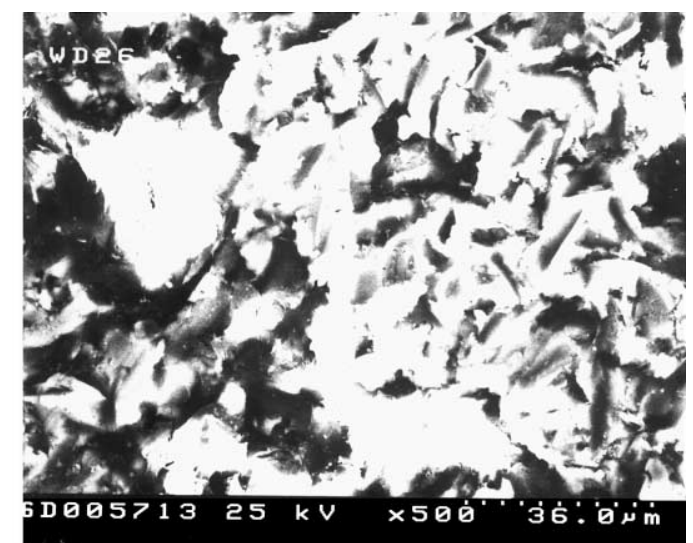

(b)

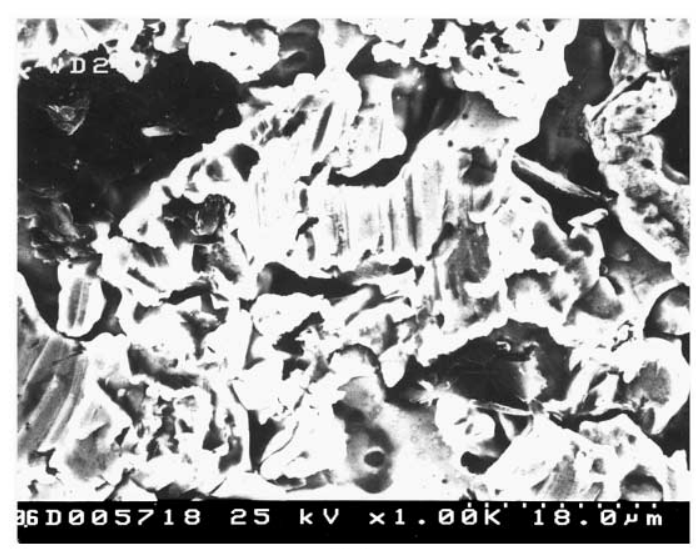

(c)

Fig. 10. Surface morphology of (a) F313; (b) M601-1; (c) M307-3 coating impacted at $30^{\circ}, 50 \mathrm{~m} / \mathrm{s}$. 


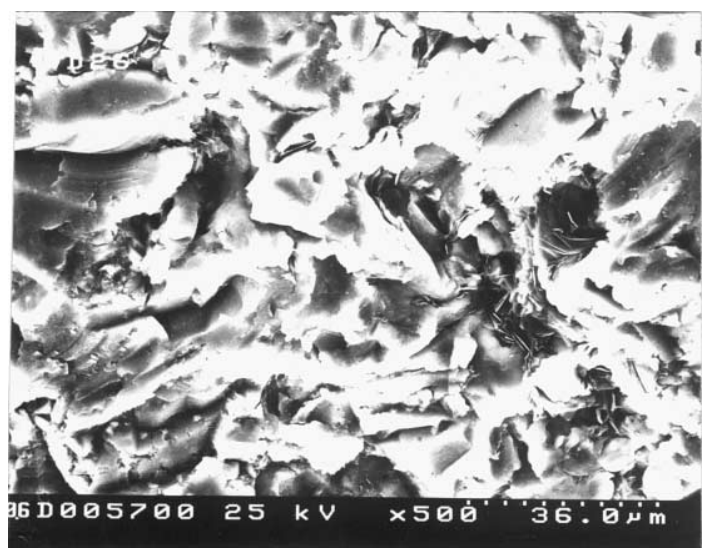

Fig. 11. Surface morphology of F313 coating impacted at $60^{\circ}, 50 \mathrm{~m} / \mathrm{s}$.

\section{Conclusions}

1. The relationship between mass loss of the abradable seal coating and erosion time is linear, and erosion inoculation period does not occur. The coatings hold a maximum erosion rate at $60^{\circ}$ impact angle. The relation between erosion rate and impact speed is an exponential function. The speed exponent increases with the increase of impact angle.

2. The mechanism of erosion wear at $90^{\circ}$ impact angle is that (1) the abrasive particles impact and extrude the surface of the coatings, and produce indentations and extruded lips, and then the lips become work-hardened by repeated impact of the particles and eventually fall off; (2) the flattened metal phase grains in the surface layer of the coating loosen and debond by repeated impact. The former effect is more remarkable in 310,313 and 601 coatings, and the latter effect is more remarkable in 307 coatings. The erosion resistance of the graphite in the coatings is extremely low and is eroded away prior to the metal phase.

3. At $30^{\circ}$ impact, the mechanism of erosion wear is micro-cutting, plowing and tunneling via pores and non-metal phase. Erosion wear at $60^{\circ}$ is somewhere in between that at $30^{\circ}$ and that at $90^{\circ}$.

\section{Acknowledgements}

The authors are grateful for the support of National Defense Science and Technology Pre-research Foundation of PR China.

\section{References}

[1] J.T. Demasi, Protective coating in the gas turbine engine, Surf. Coat. Technol 68-69 (1994) 1-9.

[2] E.R. Novinski, The design of thermal sprayed abradable seal coatings for gas turbine engines, in: Proceedings of the 4th National Thermal Spray Conference, USA, 1991, pp. 451-454.

[3] M. Yi, Friction and wear behaviour and abradability of abradable seal coating, Wear 231 (1999) 47-53.

[4] T. Oka, Basic characteristic of different abradable coatings, in: Proceedings of the International Thermal Spraying Conference, Germany, 1990, pp. 58-67.

[5] E.R. Novinski, Process parameter impact on the physical properties of an advanced abradable coating, in: Proceedings of the 3rd National Thermal Spray Conference, USA, 1990, pp. 151-157.

[6] M. Yi, Erosion wear of AlSi-graphite and Ni/graphite abradable seal coating, Trans. Nonferrons Met. Soc. China (English letter) 8 (2) (1997) 99-102.

[7] M. Dorfman, A high performance alternative to $\mathrm{NiCrAl} /$ bentonite for gas turbine abradable seals, in: Proceedings of the 13th International Thermal Spray Conference, USA, 1992, pp. 587-594.

[8] T. Chon, Aluminium-Silicon/polyester abradable coatings, in: Proceedings of the 3rd National Thermal Spray Conference, USA, 1990 , pp. 625-630.

[9] F. Ghasripoorf, R.K. Schmicl, A review of clearance control wear mechanisms for low temperature aluminium silicon alloys, in: Proceedings of the 15th International Thermal Spray Conference, France, 1998, pp. 139-144.

[10] J. Knuuttila, S. Ahmanieni, Wet abrasion and slurry erosion resistance of sealed oxide coatings, in: Proceedings of the 15th International Thermal Spray Conference, 1998, France, pp. 145-150.

[11] M. Yi, Evaluation of Al-Si/polyester abradable seal coating, Trans. Nonferrous Met. Soc. China (English letter) 6 (4) (1996) $110-113$.

[12] W. Tabakoff, Investigation of coatings at high temperature for use in turbomachinery, Surf. Coat. Technol. 40 (1989) 97-115.

[13] Lishizhou, Dong XiangLin, Erosion wear and Fretting Wear of Materials (in Chinese), Publisher of Mechanical Industry, Beijing, 1987.

[14] G.P. Tilly, The interaction of particle and material behaviour in erosion processes, Wear 16 (1970) 447-450. 